\title{
25 Years of Schur Analysis in Leipzig
}

\author{
V. E. Katsnelson • Bernd Kirstein
}

Received: 5 March 2011 / Accepted: 5 March 2011 / Published online: 20 April 2011

(C) Springer Basel AG 2011

The "25 Years of Schur Analysis in Leipzig" workshop was held from September 29 to October 1 of 2009 in honour of the 25-year anniversary of Schur Analysis in Leipzig. The journal "Complex Analysis and Operator Theory" is celebrating this anniversary with this special issue on Schur Analysis. This brief introduction to the special issue is based, in large part, on the second author's opening words to the workshop, with which he aimed to provide an overview of the turning points and topics most important to the evolution of Schur Analysis in Leipzig. Schur Analysis' development and success in Leipzig stands as one of Bernd Fritzsche and Bernd Kirstein's proudest achievements. This success was only made possible by the support and the cooperation of their longstanding colleagues from the former Soviet Union; foremost among them D. Z. Arov, V. E. Katsnelson and V. K. Dubovoj.

The history of Schur Analysis in Leipzig is best told from the beginning. Its origins as a major field of research at the University of Leipzig go back to 1984; the year after B. Fritzsche and B. Kirstein successfully defended their thesis. Their thesis defense took place in December 1983. In their thesis, they focused on various aspects of the theory of multidimensional weakly stationary sequences. At this time, both B. Fritzsche and B. Kirstein were members of a work group, mainly concerned with applying mathematical methods to problems in microelectronics. B. Fritzsche and B. Kirstein were both, in particular, occupied with problems in best linear predictions. Now beginning their postdoctoralresearch and building on their previous

Communicated by Daniel Aron Alpay.

B. Kirstein (凶)

Mathematisches Institut, Universität Leipzig, 04109 Leipzig, Germany

e-mail: Bernd.Kirstein@math.uni-leipzig.de

V. E. Katsnelson

Department of Mathematics, The Weizmann Institute, 76100 Rehovot, Israel

e-mail: victor.katsnelson@weizmann.ac.il

Birkhäuser 
work, they focused their attention on finding effective algorithms for determining best linear predictions for multivariate stationary sequences. The classical treatises of A. N. Kolmogorov, N. Wiener and P. R. Masani had a strong influence on their work during this time. Their early research soon led them to concentrate on extensions of non-negative Hermitian block Toeplitz matrices and, soon thereafter, on a similar extension problem for contractive block Toeplitz matrices.

It soon became clear that these matrix extension problems were closely related to matrix versions of classical Carathéodory or, otherwise, Schur interpolation problems. B. Fritzsche and B. Kirstein, realizing this, then proceeded to develop an approach to matrix versions of classical interpolation problems. Their approach was based on adapting the classical Schur algorithm to the matrix case. They both, furthermore, soon realized that the Schur analytic methods they had developed for non-negative Hermitian and contractive block Toeplitz matrices could, quite naturally, be generalized to apply to arbitrary non-negative Hermitian and contractive block matrices.

The University of Leipzig was proud to receive P. R. Masani (Pittsburgh) as its guest in May 1986. He would spend one month in Leipzig. His visit came to represent a significant turning point for Schur Analysis in Leipzig. During his stay, P. R. Masani suggested that V. P. Potapov's $J$-Theory might provide a sound foundation for B. Fritzsche and B. Kirstein's proposed approach to multivariate prediction theory. He further suggested contacting and collaborating with the late V. P. Potapov's remaining students in Kharkov and Odessa. Taking this advice to heart, B. Fritzsche and B. Kirstein focused their attention on $J$-Theory and, in particular, the groundwork of this theory, established in the treatises of V. P. Potapov, M. G. Krein and their students. At the same time, they secured their first connections to V. P. Potapov's Kharkov students. This very soon (in 1987) led to a visit by V. K. Dubovoj, who then spent a month as a guest researcher at the University of Leipzig. Shortly thereafter, in 1988, B. Fritzsche and B. Kirstein spent one semester (the first half of that year) at the University of Kharkov. This would only be the beginning of what was to become a long and productive partnership which continues to this day. This partnership has produced a long series of collaborations, including a monograph on the matricial Schur problem (published by Teubner) as well as a great many articles.

B. Fritzsche and B. Kirstein first met V. E. Katsnelson in Kharkov in spring of 1988. There soon followed a series of thorough and engaging discussions on various problems in Schur Analysis and it was clear that many of the ideas these discussions produced were worth pursuing. All three were determined to see these exchanges continued and focused into formal collaborations. Their efforts in this regard soon led to an invitation for V. E. Katsnelson to come to Leipzig. V. E. Katsnelson visited a foreign country for the first time when he visited Leipzig in 1989 to stay for several weeks during the months of September and October.

In January 1991, V. E. Katsnelson visited Leipzig as a docent of the University of Kharkov for the second time. He was named Wilhelm Ostwald Professor for that year and would be the last person to receive this honour for visiting researchers at the University of Leipzig. Starting the following year, the university chose, for practical reasons, no longer to offer or maintain the position.

V. E. Katsnelson spent a year in Leipzig. In the winter semester of 1991/1992, he received a guest professorship supported by the DFG. In the course of the first year of 
his stay in Leipzig, V. E. Katsnelson's German improved so much that he was able to hold his lectures for the winter semester in German. In January 1992, V. E. Katsnelson decided to accept a professorship at the Weizmann Institute in Israel, which became his new home. In the years that followed, V. E. Katsnelson would visit Leipzig many times as a guest researcher at the university, where Leipzig's Schur Analysis group often benefited from his insight. B. Fritzsche and B. Kirstein's discussions with V. E. Katsnelson have had a large influence on both the focus and the substance of their research. This is particularly true for their work on generalized Nehari interpolation, which was inspired by several articles V. E. Katsnelson published in the 1980s as well as later conversations.

In 1989, the University of Leipzig hosted the INTSEM Schur Analysis, which took place from October 15 to October 20. This conference was to become the first of twelve (as of the publication of this issue) Schur Analysis conferences in Leipzig. Three years earlier, P. R. Masani had suggested that a colloquium be organized with the intention of establishing Leipzig as a meeting place for Schur analysts from both East and West. The 1989 conference was able to fully meet these ambitions, as can be seen from the list of conference participants: P. R. Masani, A. Dijksma, H. S. V. de Snoo and S. Hassi visited the conference from the West, while Yu. L. Shmulyan, I. V. Kovalishina, V. E. Katsnelson, V. K. Dubovoj and I. M. Spitkovskii visited from the East. M. G. Krein, sadly, passed away on October 17 of 1989. This unhappy event kept D. Z. Arov from the conference until October 21. This visit would, however, also be the first of many. D. Z. Arov would later return to Leipzig many times as a visiting researcher at the university, and this led to several collaborations on block completion problems for $J$-inner functions as well as on the matricial Nehari problem.

On October 16, 1989, the INTSEM Schur Analysis participants witnessed a remarkable event. Over one hundred thousand citizens of Leipzig and its neighboring areas marched in peaceful protest against the GDR's entrenched political system. The demonstration took place in downtown Leipzig. It soon led to the deposition of the GDR's head of state and party leader, Erich Honecker. This meant that a move toward establishing proper democratic conditions in the GDR was now possible and cleared the way to German reunification. That this process deeply affected the lives of every citizen of the former GDR, goes without saying.

For the universities of the former GDR, these changes meant, first and foremost, a radical restructuring. In 1989, the majority of professorships and faculty chairs in the GDR were held by members of the communist SED party. Between 1991 and 1992 all university researchers and scientists of the former GDR were reevaluated and new applications for all research and teaching positions were being considered.

B. Fritzsche and B. Kirstein received their habilitation in 1988 with a thesis on Schur analytic methods for problems in incomplete covariance information and related interpolation problems. Both were senior assistants at, what was then, in the fall of 1989, still the Mathematics Division of the Karl Marx University of Leipzig. In the second half of the 1980s, B. Fritzsche and B. Kirstein received many invitations to attend conferences as well as for guest researcher positions at several western universities. The university did not allow them to accept even one of these invitations to the West. Neither of them was considered to have the required status for travel of this kind. That 
status was shared only by a select few, who had been specifically chosen to represent the scientific community of the GDR in the West.

Starting in 1990, the situation changed dramatically. From that point on, B. Fritzsche and B. Kirstein were allowed to take full advantage of their opportunities and communicate with leading researchers in the West. They were also able to travel, accepting invitations to the Netherlands, the Mittag-Leffler Institute in Sweden, and also to Israel and other countries.

October 1, 1992, was a particularly memorable day for B. Fritzsche and B. Kirstein. This was the day they were named professors of the Faculty of Mathematics at the University of Leipzig. Schur Analysis had put down roots in Leipzig. Since 1990, B. Fritzsche and B. Kirstein have dedicated themselves to guiding, encouraging and supporting new generations of mathematicians and scientists, as can be seen from the numerous dissertations completed under their supervision:

$\begin{array}{lll}\text { 1. } & \text { Wolfram Apitzsch } & 1991 \\ \text { 2. } & \text { Stefan Fuchs } & 1993 \\ \text { 3. } & \text { Karsten Müller } & 1994 \\ \text { 4. } & \text { Mirko Mosch } & 1999 \\ \text { 5. } & \text { Diana Michler } & 1999 \\ \text { 6. } & \text { Andreas Lasarow } & 2000 \\ \text { 7. } & \text { Abdon E. Choque-Rivero } & 2002 \\ \text { 8. } & \text { Jürgen Lorenz } & 2002 \\ \text { 9. } & \text { Uwe Raabe } & 2005 \\ \text { 10. } & \text { Sebastian Bogner } & 2005 \\ \text { 11. } & \text { Helge C. Thiele } & 2007 \\ \text { 12. } & \text { Arne Becker } & 2007 \\ \text { 13. } & \text { Conrad Mädler } & 2010 \\ \text { 14. } & \text { Kathrin Sieber } & 2010\end{array}$

Karsten Müller and Andreas Lasarow, furthermore, successfully defended their habilitation theses at the University of Leipzig in 2006 and 2008, respectively. At the end of the 1990s, Karsten Müller accepted a position at the Max Planck Institute for Cognition Sciences in Leipzig. He wrote his habilitation thesis on applications of spectral and wavelet analysis in functional magnetic resonance tomography.

Over the past decade B. Fritzsche and B. Kirstein, working closely with A. Lasarow, laid the groundwork for a Szegó theory of orthogonal rational matrix-funtions on the unit circle. Their starting points in this undertaking were, on the one hand, a theory of orthogonal rational functions on the unit circle developed by A. Bultheel, P. GonzálezVera, E. Hendriksen and $\mathrm{O}$. Njåstad and, on the other, an approach to the theory of orthogonal matrix-polynomials on the unit circle developed by P. Delsarte, Y. Genin and Y. Kamp. The latter approach is based on the methods of G. Szegó and Ya. L. Geronimus for the scalar case. In his habilitation thesis, which he defended in 2008, A. Lasarow was able to build on these results by developing a new approach to multiple Carathéodory-Nevanlinna-Pick interpolation. His approach is a generalization of B. Fritzsche and B. Kirstein's approach to the matrix versions of the Carathéodory and Schur interpolation problems. 
B. Fritzsche, B. Kirstein and A. Lasarow, furthermore, developed a new approach which encompassed both the non-degenerate and degenerate cases of the matrix versions of the Carathéodory and Schur interpolation problems. This approach used the geometry of Taylor coefficient sequences associated with Carathéodory and Schur functions. Likewise, they completed a comprehensive analysis of Weyl matrix balls related to these interpolation problems. B. Fritzsche and B. Kirstein, working together with U. Raabe and K. Sieber, later expanded this analysis to include interpolation problems for $J$-Potapov functions in the unit disk.

B. Fritzsche and B. Kirstein's work has, for many years, reflected their close ties to researchers hailing from the former Soviet Union. Their cooperation with scientists of the former USSR has resulted in many successful collaborations. First and foremost among these partnerships is certainly the one they formed with V. K. Dubovoj in 1987. Since 1987, their joint research and many collaborations (which started with their Teubner monograph, "[The] Matricial Version of the Classical Schur Problem") have led them to cover many different topics in Schur Analysis.

D. Z. Arov and V. E. Katsnelson had an equally large influence on Schur Analysis research in Leipzig. They drew B. Fritzsche and B. Kirstein's attention to various problems involving special classes of meromorphic matrix-functions and also to numerous aspects of Nehari interpolation.

In 2000, B. Fritzsche and B. Kirstein began to collaborate with Yu. M. Dyukarev on developing approaches to matrix versions of classical moment problems. Their doctoral students, A. E. Choque-Rivero, H. C. Thiele and C. Mädler also took part in and contributed to this research.

Since 2005, B. Fritzsche and B. Kirstein have been working with I. Ya. Roitberg and A. L. Sakhnovich on several topics in inverse problems. This work is part of a 36 month research project, supported by the DFG. This research has brought I. Ya. Roitberg and A. L. Sakhnovich to the University of Leipzig, where they continue their work on this project at the Mathematical Institute.

A mathematician was selected for the illustrious Leibniz Guest-Professorship at the University of Leipzig for the first time in the winter semester of 2007/2008. L. A. Sakhnovich was chosen for this great honour, endorsed by B. Fritzsche and B. Kirstein. During his tenure as Leibniz Professor, L. A. Sakhnovich collaborated with B. Fritzsche and B. Kirstein on a number of extremal problems.

There have been twelve Schur Analysis conferences in Leipzig, including the aforementioned 1989 INTSEM Schur Analysis. Among these, the "Second Days of Schur Analysis" which took place in February 1992, seemed particularly rich in new perspectives and ideas. Much of this can be attributed to Israel Gohberg's presence at the conference. His suggestions and contributions had a particular impact on Schur Analysis research in Leipzig. He was very generous with his time as well as his ideas and was always helpful and eager for discussion.

The 1994 workshop in honour of V. P. Potapov's eightieth birthday certainly remains the most memorable Schur Analysis conference held in Leipzig. The 1994 workshop sessions and lectures were collected, along with biographical material, and compiled in OT-Issue 95. This workshop most fully realized P. R. Masani's original idea of a meeting of Schur analysts of all kinds. M. S. Livsic's presence at the conference was a particular highlight. His recollections of V. P. Potapov, which he shared during the 
V. P. Potapov Memorial Session at the Wilhelm Ostwald Memorial in Großbothen, were especially touching. The generous support of the University of Leipzig and the State of Saxony made it possible to invite a large number of V. P. Potapov's former colleagues and doctoral students to Leipzig. Through their presence, the workshop participants were afforded a deeper and vivid understanding of V. P. Potapov and his life's work.

Currently, the last conference of the Leipzig Schur Analysis series remains the workshop

"25 Years of Schur Analysis in Leipzig"

29. September-1. October, 2009

to which the current special issue of CAOT is dedicated. The main ambition behind the conference was to provide an overview of Schur Analysis' progression over the past 25 years. This meant that the conference should not only provide a look back at important milestones in Schur Analysis, but also feature exceptional current research as well as discussions on the future direction of Schur Analysis along with potential research topics.

Just as in 1989 at the INTSEM Schur Analysis, P. R. Masani's initial idea was again made reality. The 2009 workshop did much to strengthen the connections between mathematicians of the former Soviet Union and their colleagues from the West. Representatives of the East included D. Z. Arov, V. K. Dubovoj, V. E. Katsnelson, A. Ya. Kheifets, S. V. Khrushchev, A. L. Sakhnovich and M. Yu. Tyaglov, while representatives of the West included D. Alpay, H. Bart, A. Dijksma, M. A. Kaashoek, W. Schempp, O. Staffans and V. Vinnikov. 